УДК 620.92

\title{
БИОЭНЕРГЕТИКА В УКРАИНЕ: СОВРЕМЕННОЕ СОСТОЯНИЕ И ПЕРСПЕКТИВЫ РАЗВИТИЯ. ЧАСТЬ 1
}

Гелетуха Г.Г., канд. тех. наук, Железная Т.А., канд. тех. наук, Кучерук П.П., Олейник Е.Н., Трибой А.B.

Институт технической теплофизики НАН Украины, ул. Желябова, 2а, Киев, 03680, Украина

Розглянуто поточний стан та прогноз розвитку біоенергетики в ЄС. Виконано оцінку потенціалу біомаси, доступної для виробництва енергії в Україні. Проаналізовано динаміку зміни потенціалу біомаси по роках.
Рассмотрено современное состояние и прогноз развития биоэнергетики в ЕС. Выполнена оценка потенциала биомассы, доступной для производства энергии в Украине. Проанализирована динамика изменения потенциала биомассы по годам.

Библ. 14, табл. 5, рис. 4.

Ключевые слова: биомасса, биотопливо, биогаз, биоэнергетика, потенциал биомассы, энергетические культуры.

АПК - агропромышленный комплекс;

БМ - биомасса;

ВИЭ - возобновляемые источники энергии;

ВКЭ - валовое конечное энергопотребление;

ТБО - твердые бытовые отходы;

\section{Развитие биоэнергетики в мире}

Возобновляемая энергетика - сектор энергетики, динамично развивающийся в мире. На сегодня доля ВИЭ в общей поставке первичной энергии в мире составляет около $13 \%$, в том числе биомассы - $10 \%$, что соответствует более 1300 млн. т н.э./год [1].

Европейский Союз успешно движется к достижению цели 2020 года по возобновляемой энергетике - 20 \% энергии из ВИЭ в валовом конечном энергопотреблении. За последние 10 лет этот показатель вырос с 8 \% до 14 \%. Три страны (Швеция, Болгария и Эстония) уже выполнили свои национальные цели 2020 года.

На сегодня объемы потребления биомассы для производства энергии в Европейском Союзе составляют более 120 млн. т н.э./год, а к 2020 году валовое конечное потребление биомассы должно вырасти до 138 млн. т н.э./год (рис. 1). Основным видом используемой биомассы является твердая н.э. - нефтяной эквивалент;

c/х - сельское хозяйство;

сух. т - тонн сухого вещества.

\section{Нижние индексы:}

э - электрический.

биомасса. Ее доля в общем объеме потребления неизменно составляет около $70 \%$.

Вклад биомассы в валовое конечное энергопотребление ЕС уже превысил 8 \%, а к 2020 году должен вырасти до 14 \% (табл. 1). В отдельных странах-лидерах уровень развития биоэнергетики значительно выше среднеевропейского. Так, в Финляндии доля биомассы в конечном энергопотреблении составляет 28 \%, в Латвии - более 27 \%, в Швеции и Эстонии - около $26 \%$ (для сравнения - в Украине 1,78 \%). Австрия и Эстония на сегодня уже практически выполнили свои обязательства 2020 года по вкладу биомассы в валовое конечное энергопотребление (табл. 2).

Наибольшие успехи достигнуты в секторе тепловой энергии - биомасса обеспечивает почти $16 \%$ общего объема генерации, что соответствует третьему месту после природного газа $(43 \%)$ и угля $(28,5 \%)$ (рис. 2). При этом из биомассы производится более $95 \%$ всей возобнов- 


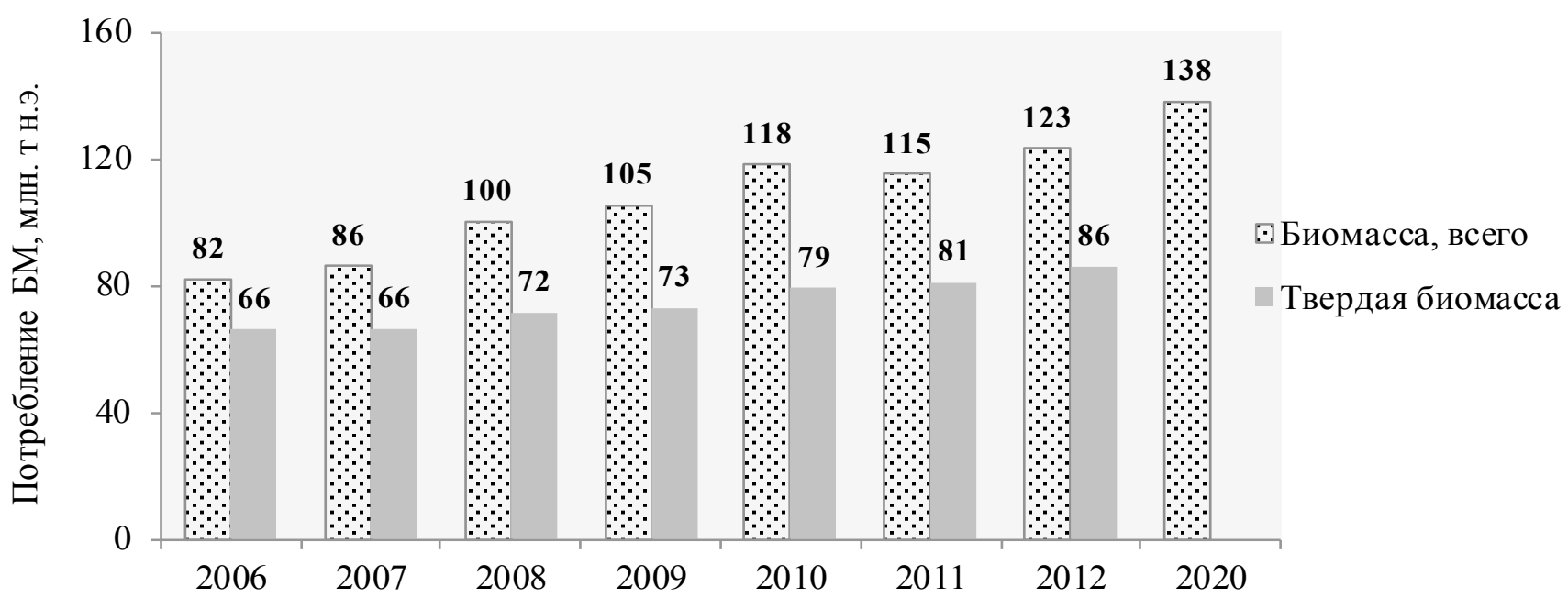

2020 2. - иель ЕС по валовому конечному потреблению биомассы согласно Национальным планам действий по возобновляемой энергетике

Рис. 1. Динамика общего потребления биомассы для производства энергии в ЕС [2-6].

Табл. 1. Фактическая и прогнозная доля ВИЭ и биомассы в энергобалансе ЕС $[3,6,7]$

\begin{tabular}{|l|c|c|}
\hline \multicolumn{1}{|c|}{ Показатели } & $2011-2012$ гг., \% & 2020 г., \% (прогноз) \\
\hline Доля ВИЭ в валовом конечном энергопотреблении & 14,1 & 20 \\
\hline Доля биомассы в валовом конечном энергопотреблении & 8,4 & 14 \\
\hline Доля ВИЭ в валовом производстве тепловой энергии & 16,5 & 20 \\
\hline Доля биомассы в валовом производстве тепловой энергии & 15,8 & $18 \ldots 19$ \\
\hline Доля ВИЭ в валовом производстве электроэнергии & 23,5 & 34 \\
\hline Доля биомассы в валовом производстве электроэнергии & 4,0 & 7 \\
\hline Доля ВИЭ в транспортном секторе & 5,1 & 10 \\
\hline Доля биомассы в транспортном секторе & 5,0 & $\sim 10 \%$ \\
\hline
\end{tabular}

ляемой тепловой энергии. В ряде стран доля производства тепловой энергии из биомассы гораздо выше среднеевропейской: Швеция - $60 \%$, Австрия $-31 \%$, Финляндия - $27 \%$, Дания $-25 \%$.

Анализ структуры производства электроэнергии в ЕС показывает, что объем «зеленой» электроэнергии устойчиво растет - с около $300 \mathrm{TBT} \cdot ч$ (12,5\% общего объема производства) в 1990 г. до более $700 \mathrm{TВт \cdot ч}(23,5 \%)$ в 2012 г. При этом объемы генерации электроэнергии из нефтепродуктов снижаются, из природного газа - растут с некоторой стабилизацией в последние годы, а использование угля и атомной энергии в целом остается примерно на одинаковом уровне.

Вклад биомассы в секторе электроэнергии Европейского Союза более скромный - 4 \% общего объема генерации и $19 \%$ от всех ВИЭ (рис. 3). В отдельных странах этот вклад существенно выше: в Финляндии из биомассы вырабатывается 15,3 \% общего объема электроэнергии, в Дании - 12,4 \%, в Швеции $-7,7$ \%, в Австрии $-6,9 \%$.

Основным видом биомассы для производства электроэнергии в ЕС является древесина установленная мощность оборудования, работающего на ней, составляет почти 17 ГВт. . Также 
Табл. 2. Фактический и прогнозный вклад биомассы в ВКЭ в странах ЕС [3]

\begin{tabular}{|c|c|c|c|c|c|}
\hline \multirow{2}{*}{ Страны EC } & \multirow{2}{*}{$\begin{array}{c}\text { ВКЭ, } 2011 \text { г. } \\
\text { тыс. т н.э. }\end{array}$} & \multicolumn{2}{|c|}{ Вклад БМ в ВКЭ, 2011 г. } & \multicolumn{2}{|c|}{ Вклад БМ в ВКЭ, 2020 г. (цель) } \\
\hline & & тыс. т н.э. & \% от ВКЭ & тыс. т н.э. & \% от ВКЭ \\
\hline EC-28 & 1103260 & 92599 & 8,39 & 138312 & 12,54 \\
\hline Бельгия & 38886 & 1639 & 4,21 & 3772 & 9,70 \\
\hline Болгария & 9287 & 962 & 10,36 & 1344 & 14,47 \\
\hline Чешская Республика & 24634 & 2193 & 8,90 & 3671 & 14,90 \\
\hline Дания & 14679 & 2769 & 18,86 & 3665 & 24,97 \\
\hline Германия & 207093 & 16240 & 7,84 & 20908 & 10,10 \\
\hline Эстония & 2843 & 730 & 25,68 & 726 & 25,54 \\
\hline Ирландия & 10800 & 321 & 2,97 & 1054 & 9,76 \\
\hline Греция & 18835 & 1163 & 6,17 & 1947 & 10,34 \\
\hline Испания & 86532 & 5898 & 6,82 & 9311 & 10,76 \\
\hline Франция & 148065 & 12043 & 8,13 & 21431 & 14,47 \\
\hline Хорватия & 6181 & 445 & 7,20 & нет данных & нет данных \\
\hline Италия & 122312 & 6838 & 5,59 & 9765 & 7,98 \\
\hline Кипр & 1896 & 41 & 2,16 & 80 & 4,22 \\
\hline Латвия & 3982 & 1099 & 27,60 & 1543 & 38,75 \\
\hline Литва & 4696 & 916 & 19,51 & 1295 & 27,58 \\
\hline Люксембург & 4276 & 93 & 2,17 & 328 & 7,67 \\
\hline Венгрия & 16276 & 1332 & 8,18 & 2069 & 12,71 \\
\hline Мальта & 446 & 1 & 0,22 & 14 & 3,14 \\
\hline Нидерланды & 50663 & 1581 & 3,12 & 3143 & 6,20 \\
\hline Австрия & 27328 & 4566 & 16,71 & 4540 & 16,61 \\
\hline Польша & 64689 & 5883 & 9,09 & 8214 & 12,70 \\
\hline Португалия & 17350 & 2706 & 15,60 & 3101 & 17,87 \\
\hline Румыния & 22576 & 3620 & 16,03 & 4365 & 19,33 \\
\hline Словения & 4951 & 558 & 11,27 & 776 & 15,67 \\
\hline Словакия & 10795 & 774 & 7,17 & 1022 & 9,47 \\
\hline Финляндия & 25179 & 7076 & 28,10 & 8280 & 32,88 \\
\hline Швеция & 32168 & 8539 & 26,55 & 11583 & 36,01 \\
\hline Великобритания & 132023 & 3021 & 2,29 & 10368 & 7,85 \\
\hline
\end{tabular}

в больших объемах используется биогаз (7191 МВт) и бытовые отходы (6158 МВт ). Электроэнергия из жидких биотоплив (1102 МВт ) производится только в отдельных странах, например, в Италии и Германии.

\section{Потенциал биомассы в Украине}

Украина имеет большой потенциал биомассы, доступной для производства энергии, что является хорошей предпосылкой для динамичного развития сектора биоэнергетики. Экономи- 


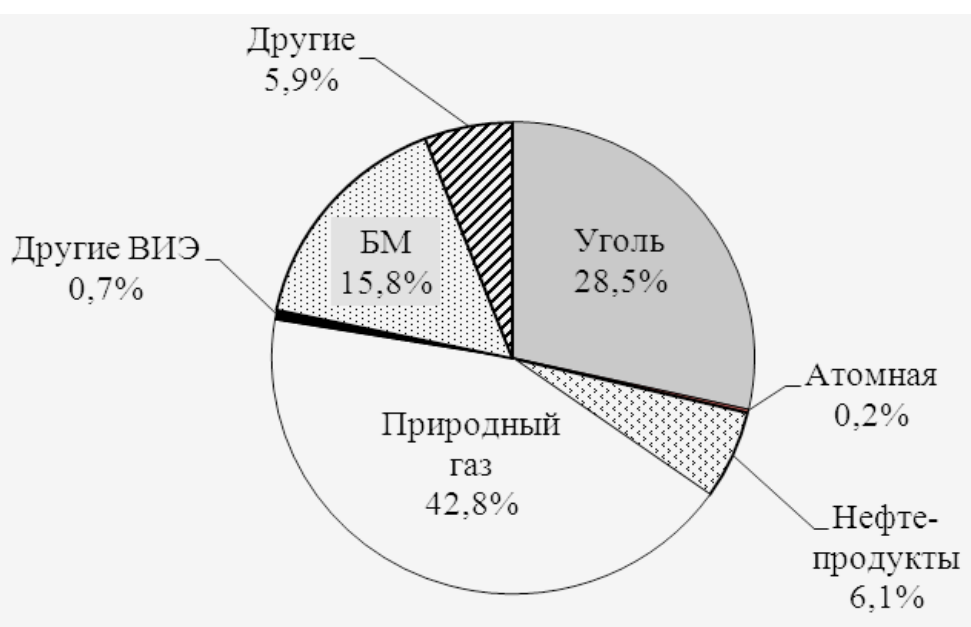

Рис. 2. Структура производства тепловой энергии в ЕС, 2011 г. [6].

чески целесообразный энергетический потенциал биомассы в стране составляет порядка $20 \ldots$ 25 млн. т у.т./год. Основными составляющими потенциала являются отходы сельскохозяйственного производства (солома, стебли кукурузы, стебли подсолнечника и т.п.) - более 11 млн. т у.т./ год (по данным 2013 г.) и энергетические культуры - около 10 млн. т у.т./год (табл. 3).

При этом сельскохозяйственные отходы являются реальной частью потенциала биомассы, а данные по энергетическим культурам отражают объем биомассы, который можно получить при выращивании этих культур на свободных землях в Украине. Следует отметить, что этот процесс активно развивается несколько последних лет. Оценка потенциала является консервативной и включает основные виды биомассы, имеющие значительное влияние на объем потенциала. На практике источников биомассы намного больше - отходы зерноочистки элеваторов, ботва сахарной свеклы, биомасса камыша и другие.

Площадь незадействованных сельскохозяйственных земель в Украине составляет 3...4 млн. га, по данным 2012 года - 3,5 млн. га (табл. 4). Несколько возможных сценариев выращивания энергетических культур на этих землях представлены в таблице 5. Сценарии отличаются между собой площадью земель, выделенных под выращивание энергетических культур - 1 млн. га, 2 млн. га и 3 млн. га. Для всех сценариев выбраны 4 наиболее перспективные культуры ива, мискантус, тополь, кукуруза и следующее распределение общей площади: ива - $25 \%$, мискантус $-15 \%$, тополь - $10 \%$, кукуруза - $50 \%$. Предложенный перечень культур является одним из возможных вариантов, выбранным для данной оценки потенциала биомассы. На практике, исходя из конкретных условий, могут выращиваться и другие культуры, например, сахарное сорго.

Величина энергетического потенциала биомассы в Украине колеблется по годам и зависит главным образом от урожайности основных сельскохозяйственных культур. В 2013 г. был собран рекордный за последние 20 лет урожай зерновых и зернобобовых культур (63 млн. т), поэтому экономический потенциал биомассы также достиг своего максимального значения - почти 28 млн. т у.т. (рис. 4). Напротив, 2003 год был одним из самых неурожайных по зерновым культурам (20 млн. т), и потенциал биомассы упал до 18,5 млн. т у.т.

При оценке потенциала чрезвычайно важным является вопрос, какую долю отходов/ остатков сельскохозяйственного производства можно использовать на энергетические нужды без негативного влияния на плодородие почв. Эксперты Биоэнергетической ассоциации Украины, выполнив соответствующее исследование, пришли к выводу, что в среднем для Украины можно прогнозировать использование до $30 \%$ теоретического потенциала соломы зерновых культур и до 40 \% теоретического 
Табл. 3. Энергетический потенциал биомассы в Украине, 2013 г.

\begin{tabular}{|c|c|c|c|}
\hline Вид биомассы & $\begin{array}{l}\text { Теоретический } \\
\text { потенциал, млн. т }\end{array}$ & $\begin{array}{c}\text { Доля, доступная } \\
\text { для получения } \\
\text { энергии, \% }\end{array}$ & $\begin{array}{c}\text { Экономический } \\
\text { потенциал, } \\
\text { млн. т у.т. }\end{array}$ \\
\hline Солома зерновых культур & 30,6 & 30 & 4,54 \\
\hline Солома рапса & 4,2 & 40 & 0,84 \\
\hline $\begin{array}{l}\text { Отходы производства кукурузы на зерно } \\
\text { (стебли, стержни початков) }\end{array}$ & 40,2 & 40 & 4,39 \\
\hline $\begin{array}{l}\text { Отходы производства подсолнечника (стеб- } \\
\text { ли, корзинки) }\end{array}$ & 21,0 & 40 & 1,72 \\
\hline Вторичные отходы с/х (шелуха, жом) & 6,9 & 75 & 1,13 \\
\hline $\begin{array}{l}\text { Древесная биомасса (дрова, порубочные } \\
\text { остатки, отходы деревообработки) }\end{array}$ & 4,2 & 90 & 1,77 \\
\hline Биодизель (из рапса) & - & - & 0,47 \\
\hline Биоэтанол (из кукурузы и сахарной свеклы) & - & - & 0,99 \\
\hline $\begin{array}{l}\text { Биогаз из отходов и побочной продукции } \\
\text { АПК }\end{array}$ & $\begin{array}{c}1,6 \text { млрд. }{ }^{3} \\
\text { метана }\left(\mathrm{CH}_{4}\right)\end{array}$ & 50 & 0,97 \\
\hline Биогаз с полигонов ТБО & 0,6 млрд. м $\mathrm{CH}_{4}$ & 34 & 0,26 \\
\hline $\begin{array}{l}\text { Биогаз из сточных вод (промышленных и } \\
\text { коммунальных) }\end{array}$ & 1,0 млрд. м ${ }^{3} \mathrm{CH}_{4}$ & 23 & 0,27 \\
\hline $\begin{array}{l}\text { Энергетические культуры**: } \\
\text { - ива, тополь, мискантус } \\
\text { - кукуруза (биогаз) }\end{array}$ & $\begin{array}{c}11,5 \\
3,3 \text { млрд. } \mathrm{M}^{3} \mathrm{CH}_{4} \\
\end{array}$ & $\begin{array}{l}90 * \\
90 * \\
\end{array}$ & $\begin{array}{l}6,28 \\
3,68\end{array}$ \\
\hline Topф & - & - & 0,40 \\
\hline Всего & - & - & 27,71 \\
\hline
\end{tabular}

* Учитываются потери при сборе урожая.

** Согласно сценарию II (табл. 5).

Табл. 4. Структура сельскохозяйственных земель в Украине, 2012 г. [8]

\begin{tabular}{|l|c|}
\hline \multicolumn{1}{|c|}{ Категория земель } & Площадь, млн. га \\
\hline Сельскохозяйственные угодья, в том числе: & 41,5 \\
\hline пахотные земли (I) & 32,5 \\
\hline сенокосы & 2,4 \\
\hline пастбища & 5,5 \\
\hline Посевная площадь (II), в том числе: & 27,8 \\
\hline зерновые и зернобобовые культуры & 15,4 \\
\hline технические культуры & 7,8 \\
\hline картофель и овощебахчевые культуры & 2,0 \\
\hline кормовые культуры & 2,5 \\
\hline Площадь чистых паров (III) & 1,2 \\
\hline Незадействованные пахотные земли (I - II - III) (оценка авторов) & 3,5 \\
\hline
\end{tabular}


Табл. 5. Возможные сценарии выращивания энергетических культур в Украине

\begin{tabular}{|c|c|c|c|}
\hline \multirow{2}{*}{ Показатели } & \multicolumn{3}{|c|}{ Сценарии } \\
\hline & $\mathrm{I}$ & II & III \\
\hline Площадь под энергетическими культурами (всего), млн. га & 1 & 2 & 3 \\
\hline \multicolumn{4}{|l|}{ Структура площзадей по культурам, млн. га: } \\
\hline - ива & 0,25 & 0,5 & 0,75 \\
\hline - мискантус & 0,15 & 0,3 & 0,45 \\
\hline - тополь & 0,1 & 0,2 & 0,30 \\
\hline - кукуруза (на биогаз) & 0,5 & 1,0 & 1,5 \\
\hline $\begin{array}{l}\text { Экономический потенциал энергетических культур (всего), млн. } \\
\text { т у.т./год }\end{array}$ & 4,98 & 9,95 & 14,93 \\
\hline \multicolumn{4}{|l|}{ Структура потенцииала по культурам, млн. $m$ у.m./год: } \\
\hline - ива & 1,66 & 3,32 & 4,98 \\
\hline - мискантус & 0,94 & 1,88 & 2,82 \\
\hline - тополь & 0,54 & 1,08 & 1,62 \\
\hline - кукуруза (на биогаз) & 1,84 & 3,68 & 5,51 \\
\hline \multicolumn{4}{|l|}{ Показатели, используемые в сценариях } \\
\hline \multicolumn{4}{|l|}{ Распределение общей площади под энергокультурами, \% } \\
\hline - ива & \multicolumn{3}{|c|}{25} \\
\hline - мискантус & \multicolumn{3}{|c|}{15} \\
\hline - тополь & \multicolumn{3}{|c|}{10} \\
\hline - кукуруза (на биогаз) & \multicolumn{3}{|c|}{50} \\
\hline \multicolumn{4}{|l|}{ Урожайность*, сух. т/га в год: } \\
\hline - ива & \multicolumn{3}{|c|}{$12[9]$} \\
\hline - мискантус & \multicolumn{3}{|c|}{$12[10]$} \\
\hline - тополь & \multicolumn{3}{|c|}{$9,5[11]$} \\
\hline - кукуруза на биогаз (свежая масса) & \multicolumn{3}{|c|}{$30[12]$} \\
\hline \multicolumn{4}{|l|}{ Теплота сгорания (сухой массы), МДж/кг: } \\
\hline - ива & \multicolumn{3}{|c|}{18} \\
\hline - мискантус & \multicolumn{3}{|c|}{17} \\
\hline - тополь & \multicolumn{3}{|c|}{18,5} \\
\hline - кукуруза на биогаз & \multicolumn{3}{|c|}{$\begin{array}{c}\text { выход } \mathrm{CH}_{4}: 100 \text { м3/т силоса* } \\
\text { содержание } \mathrm{CH}_{4} \text { в биогазе: } 55 \%\end{array}$} \\
\hline
\end{tabular}

* Консервативный подход.

потенциала отходов производства кукурузы на зерно и подсолнечника $[13,14]$. На уровне конкретного сельскохозяйственного предприятия или фермерского хозяйства этот вопрос должен решаться индивидуально, принимая во внимание существующие неэнергетические направления применения соломы и других растительных отходов (например, использование в 


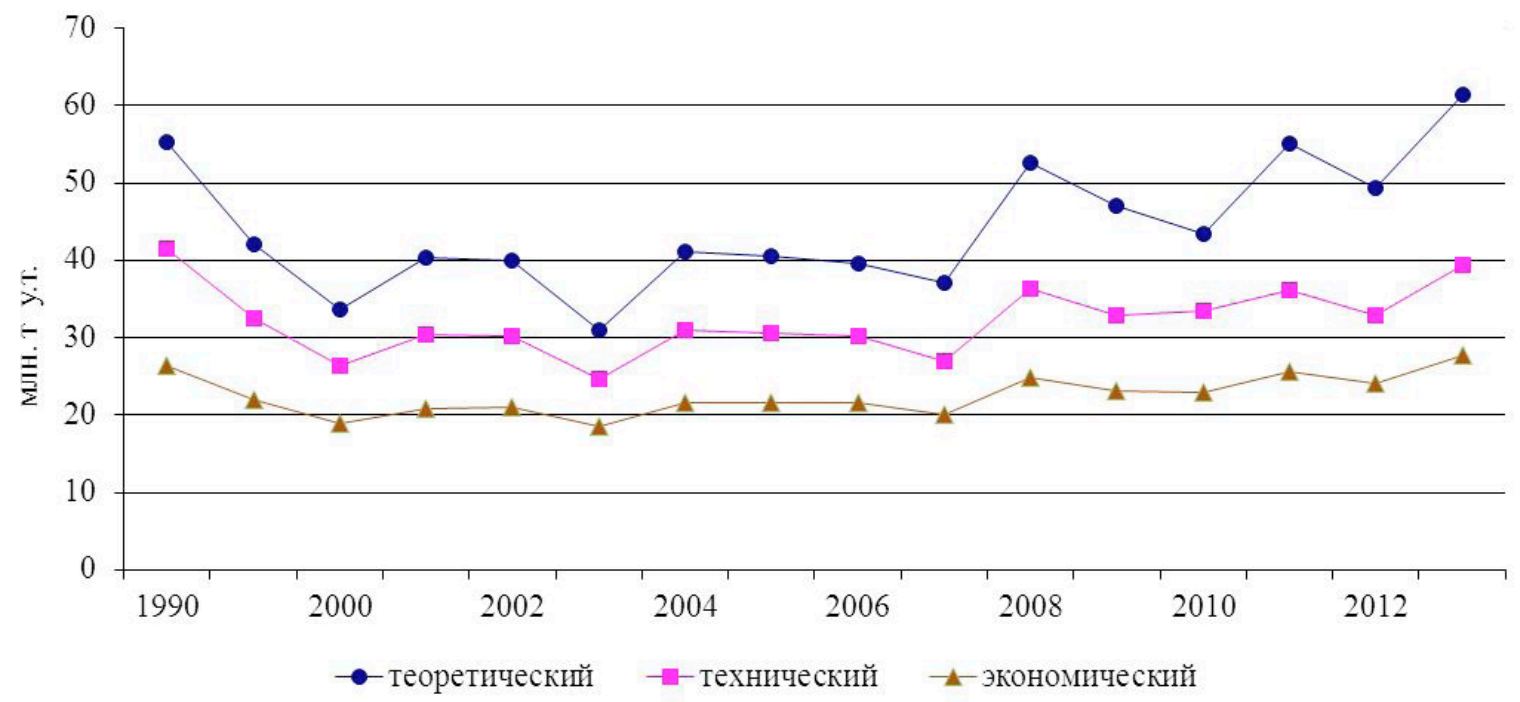

Рис. 4. Динамика энергетического потенциала биомассы в Украине.

качестве органического удобрения, подстилки и корма для скота).

\section{Выводы}

Возобновляемая энергетика - сектор энергетики, динамично развивающийся в мире. На сегодня доля ВИЭ в общей поставке первичной энергии в мире составляет около $13 \%$, в том числе биомассы - $10 \%$, что соответствует более 1300 млн. т н.э./год.

Европейский Союз успешно движется к достижению цели 2020 года по возобновляемой энергетике - $20 \%$ энергии из ВИЭ в валовом конечном энергопотреблении. За последние 10 лет этот показатель вырос с 8 \% до $14 \%$. Вклад биомассы в валовое конечное энергопотребление ЕС уже превысил $8 \%$, а к 2020 году должен вырасти до 14 \%. Наибольшие успехи достигнуты в секторе тепловой энергии - биомасса обеспечивает почти $16 \%$ общего объема генерации, что соответствует третьему месту после природного газа и угля. Вклад биомассы в секторе электроэнергии ЕС более скромный - 4 \% общего объема генерации и $19 \%$ от всех ВИЭ.

Украина имеет большой потенциал биомассы, доступной для производства энергии, что является хорошей предпосылкой для динамичного развития сектора биоэнергетики. Экономически целесообразный энергетичес- кий потенциал биомассы в стране составляет порядка 20...25 млн. т у.т./год. Основными составляющими потенциала являются отходы сельскохозяйственного производства (солома, стебли кукурузы, стебли подсолнечника и т.п.) - более 11 млн. т у.т./год (по данным 2013 г.) и энергетические культуры - около 10 млн. т у.т./ год.

Для Украины биоэнергетика является одним из стратегических направлений развития сектора возобновляемых источников энергии, учитывая высокую зависимость страны от импортных энергоносителей, в первую очередь, природного газа, и большой потенциал биомассы, доступной для производства энергии. К сожалению, темпы развития биоэнергетики в Украине до сих пор существенно отстают от европейских. На сегодняшний день доля биомассы в общей поставке первичной энергии в стране составляет лишь $1,2 \%$, а в валовом конечном энергопотреблении (по оценке авторов) $-1,78 \%$.

\section{ЛИТЕРАТУРА}

1. Key World Energy Statistics. Publication of the International Energy Agency, 2013.

2. Annual Statistical Report on the contribution of biomass to the energy system in the EU27. Prepared by AEBIOM, 2011.

3. European Bioenergy Outlook. Report by 
AEBIOM, 2013.

4. Solid Biomass Barometer. Report by Eur Observ'ER, December 2013.

5. Solid Biomass Barometer. Report by Eur Observ'ER, December 2012.

6. EU Energy in Figures. Publication of the European Commission, 2013.

7. Renewable Energy Road Map. Renewable energies in the 21st century: building a more sustainable future. COM (2006) 848 final, Brussels, 10.01.2007.

8. Статистический ежегодник Украины за 2012 год. Публикация Государственной службы статистики Украины под ред. Осауленко А.Г., Киев, 2013, - 551 с.

9. Svitlana Trybush. Willow for Energy: Myths and Reality. Proc. of 8th International Conference on Biomass for Energy, 25-26 September 2012, Kyiv, Ukraine.

10. Блюм Я.Б., Гелетуха Г.Г., Григорюк И.П. $u \partial p$. Новейшие технологии биоэнергоконверсии. - К: «Аграр Медиа Груп», 2010. - 326 с.

\section{BIOENERGY IN UKRAINE: STATE OF THE ART AND PROSPECTS FOR DEVELOPMENT. PART 1}

\section{Geletukha G.G., Zheliezna T.A., Kucheruk P.P., Oliinyk Ye. N., Tryboi O.V.}

Institute of Engineering Thermophysics of the National Academy of Sciences of Ukraine, vul. Zhelyabova, 2a, Kyiv, 03680, Ukraine

The paper covers state of the art and outlook for bioenergy development in the EU. The contribution of biomass to the final energy con-
11. Я.Д. Фучило, М.В. Сбитна, О.Я. Фучило, B.H. Литвин. Опыт и перспективы выращивания тополя (POPULUS SP.L.) в южной степи Украины // Научные труды Лесной академии наук Украины: сборник научных трудов. -2009. Вып. 7. - С. 66 - 69.

12. Гелетуха Г.Г., Кучерук П.П., Матвеев Ю.Б. и др. Развитие биогазовых технологий в Украине и Германии: нормативно-правовое поле, состояние и перспективы. Киев-Гюльцов: FNR, 2013, $-71 \mathrm{c}$.

13. Гелетуха Г.Г., Железная Т.А., Трибой А.В. Перспективы использования отходов сельского хозяйства для производства энергии в Украине. Часть $1 / /$ Промышленная теплотехника. -2014. - T. 36, № 4. - C. 36-42.

14. Гелетуха Г.Г., Железная Т.А., Трибой А.В. Перспективы использования отходов сельского хозяйства для производства энергии в Украине. Часть 2 // Промышленная теплотехника. -2014. - Т. 36, № 5. - C. 73-80.

sumption as well as to heat and power sectors of the EU countries is analyzed. It is shown that application of bioenergy technologies is most successful in heat production while contribution of biomass to power production is more modest. Potential of biomass available for energy production in Ukraine is assessed. Dynamics of the biomass potential over years is analyzed. Main parts of the bioenergy potential are primary and secondary agricultural residues and energy crops. The agricultural residues are a real part of the biomass potential, and the presented data on energy crops show how much biomass can be obtained by growing energy crops on unused ag- 
ricultural land in Ukraine. The paper proposes three possible scenarios for raising energy crops in Ukraine.

References 14, tables 5, figures 4 .

Key words: biomass, biofuel, biogas, bioenergy, potential of biomass, energy crops.

1. Key World Energy Statistics. Publication of the International Energy Agency, 2013.

2. Annual Statistical Report on the contribution of biomass to the energy system in the EU27. Prepared by AEBIOM, 2011.

3. European Bioenergy Outlook. Report by AEBIOM, 2013.

4. Solid Biomass Barometer. Report by Eur Observ'ER, December 2013.

5. Solid Biomass Barometer. Report by Eur Observ'ER, December 2012.

6. EU Energy in Figures. Publication of the European Commission, 2013.

7. Renewable Energy Road Map. Renewable energies in the 21 st century: building a more sustainable future. COM (2006) 848 final, Brussels, 10.01.2007.

8. Statistical Yearbook of Ukraine for 2012. Publication by the State Statistics Service of Ukraine edited by A.G. Osaulenko, Kyiv. - 2013, -551 p. (Ukr.)
9. Svitlana Trybush. Willow for Energy: Myths and Reality. Proc. of 8th International Conference on Biomass for Energy, 25-26 September 2012, Kyiv, Ukraine.

10. Blium Ya.B., Geletukha G.G., Grygoriuk I.P. at al. Modern technologies for bioenergy conversion. - K: «AgrarMe-diaGroup», 2010. $326 \mathrm{p}$.

11. Ya.D. Fuchylo, M.V. Sbytna, O.Ya. Fuchylo, V.M. Litvin. Experience and prospects for growing poplar (POPULUSSP.L.) in southern steppe of Ukraine // Proceedings of the Forest Academy of Sciences of Ukraine. - 2009. Issue 7, P. 66 - 69.

12. Geletukha G.G., Kucheruk P.P., Matveev $Y u . B$. at al. Development of biogas technologies in Ukraine and Germany: regulatory and legal framework, status and prospects. Kyiv-Gülzow: FNR, 2013, 71 p. (Rus.)

13. Geletukha G.G., Zheliezna T.A., Tryboi $O$.V. Prospects for the use of agricultural residues for energy production in Ukraine. Part $1 / /$ Promyshlennaya teplotekhnika. - 2014. - V. 36, № 4. - P. 36-42. (Rus.)

14. Geletukha G.G., Zheliezna T.A., Tryboi O.V. Prospects for the use of agricultural residues for energy production in Ukraine. Part 2 // Promyshlennaya teplotekhnika. - 2014. - V. 36, № 5. - P. 73-80. (Rus.) 